\title{
Galanin-like peptide as a link in the integration of metabolism and reproduction
}

\author{
Michelle L. Gottsch ${ }^{1}$, Donald K. Clifton ${ }^{2}$ and Robert A. Steiner ${ }^{1,2,3}$ \\ ${ }^{1}$ Department of Physiology and Biophysics, University of Washington, Box 357290, Seattle WA 98195-7290, USA \\ ${ }^{2}$ Department of Obstetrics and Gynecology, University of Washington, Box 356460, Seattle, WA 98195, USA \\ ${ }^{3}$ Department of Biology, University of Washington, Box 357290, Seattle, WA 98195-7290, USA
}

\begin{abstract}
The arcuate nucleus is a hypothalamic center that couples energetics and reproduction. Peptide-releasing neurons in the arcuate nucleus receive and process humoral signals from the periphery and relay this information to other nuclei in the hypothalamus and preoptic area. Galanin-like peptide (GALP) is expressed in the arcuate nucleus, and GALP-containing neurons are targets for the action of leptin. GALP-containing neurons are closely apposed to gonadotropin-releasing hormone (GnRH) neurons in the preoptic area, and CNS injections of GALP stimulate GnRH-mediated secretion of luteinizing hormone. These observations indicate that GALP is a molecular signal that couples circulating indices of metabolism to the neuroendocrine reproductive system and, thus, regulates reproductive activity as a function of the energy state. In this article, we describe the involvement of GALP in metabolism and reproduction, and in the coupling between these two processes.
\end{abstract}

The brain has a remarkable ability to sense the status of metabolic fuel reserves and defend their adequacy by adjusting appetite and metabolism to maintain an appropriate body weight. Moreover, the brain governs the activity of the reproductive system as a function of these metabolic reserves and enables activation of the hypothalamic-pituitary-gonadal axis only when fuel stores are deemed adequate to support the energetic requirements of reproduction. The arcuate nucleus (Arc) in the hypothalamus is a node for this physiological integration. Recently, a newly identified peptide in the Arc has been shown to modulate both feeding behavior and reproduction, which unveils a new link in the integration of metabolism and reproduction. In this review, we discuss the emerging role of this peptide, known as galanin-like peptide (GALP), in the physiological integration of metabolism and reproduction.

\section{The Arc integrates metabolism and reproduction}

The Arc comprises the neuronal circuitry required for the neuroendocrine integration of metabolism and reproduction [1]. Two populations of neurons in the Arc play key

Corresponding author: R.A. Steiner (steiner@u.washington.edu). roles in the regulation of these physiological processes. One population produces neuropeptide Y (NPY) and agouti-related peptide (AgRP), whereas the other produces $\alpha$-melanocyte-stimulating hormone ( $\alpha$-MSH) and $\beta$-endorphin from a common precursor, proopiomelanocortin (POMC), and cocaine- and amphetamine-regulated transcript (CART). These two cell groups (NPY/AgRP and POMC/CART) are regulated differentially by metabolic hormones such as leptin and insulin, and act in opposition to control appetite, body weight and metabolic rate [1-4]. NPY/AgRP and POMC/CART neurons send axonal projections to the paraventricular nucleus (PVN), lateral hypothalamus, and areas in the midbrain and hindbrain to regulate the circuitry that controls complex behaviors, such as feeding, and adjust the metabolic rate to maintain body weight homeostasis [3,5-7]. Disruption of these networks leads to the dysregulation of body weight and disturbances in metabolism [8]. The Arc is also an important center for the neuroendocrine control of reproduction [9]. NPY and the products of POMC $(\alpha$-MSH and $\beta$-endorphin) have important effects on the secretion of gonadotropin-releasing hormone $(\mathrm{GnRH})$ and gonadotropins $[8,10,11]$, and they are regulated by sex steroids $[12,13]$. Thus, NPY/AgRP and POMC/CART cells have well established roles in the control of both body weight and reproduction. Recently, evidence has accumulated indicating that GALP might also be an important regulator of metabolism and reproduction.

\section{Galanin and its receptors}

Galanin was discovered in 1983 [14]. This neuropeptide comprises 29-30 amino acids (depending on species) and has a highly conserved N-terminal (amino acids $1-13$ ) that confers its biological activity [15]. Galanin is distributed widely throughout the brain (including the Arc), spinal cord and gut [16], and is coreleased with other neuropeptides such as GnRH, growth hormone-releasing hormone (GHRH) and vasopressin, and classical neurotransmitters such as noradrenaline [17-20]. Galanin is implicated in many physiological processes, including feeding, nociception, nerve regeneration, memory, neuroendocrine function, and the regulation of secretion and contractility in the gut [21-24]. The three known subtypes of galanin receptor are membrane-bound G-protein-coupled receptors [25]. These 
Table 1. Comparison of galanin and GALPa

\begin{tabular}{|c|c|c|c|}
\hline & Galanin & GALP & Refs \\
\hline Length & $29-30$ residues & 60 residues & {$[15,26]$} \\
\hline \multirow[t]{4}{*}{ Receptors } & GaIR1 & GaIR1 & {$[25]$} \\
\hline & GalR2 & GalR2 (high affinity) & {$[21]$} \\
\hline & GalR3 & GALP receptor? & \\
\hline & & Other receptors? & \\
\hline Functions & $\begin{array}{l}\text { Feeding, nociception, nerve regeneration, memory, } \\
\text { neuroendocrine secretion, gut secretion and } \\
\text { motility and reproduction }\end{array}$ & Regulates $\mathrm{Fl}, \mathrm{BW}$ and reproduction & {$[22,24,25]$} \\
\hline CNS location & Several regions in the brain and spinal cord & Arc and ME & {$[16,35,37]$} \\
\hline PNS location & Gut & Neurohypophysis & {$[14,39]$} \\
\hline \multirow[t]{3}{*}{ Chromosomal loci } & Human, 11q13.3 & Human, 19q13.43 & {$[27,35]$} \\
\hline & Mouse, 192.0 & Mouse, 7A1 & \\
\hline & Rat, 1q42 & Rat, 1q12 & \\
\hline $\begin{array}{l}\text { Fos induction after i.c.v. } \\
\text { injection }\end{array}$ & mPOA, PVN, Arc & mPOA, PVN, Arc, hDBB, ME & {$[30,31]$} \\
\hline $\begin{array}{l}\text { Effects on food intake } \\
\text { and body weight }\end{array}$ & Stimulates feeding in satiated rats & $\begin{array}{l}\text { In rats, initially stimulates } \mathrm{FI} \text {, } \\
\text { followed by a decrease in } \mathrm{FI} \text { and } \mathrm{BW} \text {. } \\
\text { In mice, inhibits } \mathrm{FI} \text { and } \mathrm{BW}\end{array}$ & {$[50,51]$} \\
\hline Effect of leptin & Inhibits & Induces & [29] \\
\hline Effect of insulin & Inhibits & Induces & {$[62]$} \\
\hline Sexual dimorphism & Higher in females. Responds to estradiol & Unresponsive to sex steroids & {$[28,69]$} \\
\hline $\begin{array}{l}\text { Association with GnRH- } \\
\text { positive neurons }\end{array}$ & In rats, GnRH-positive neurons contain galanin & $\begin{array}{l}\text { In rats, GALP-positive neurons } \\
\text { project to GnRH-positive neurons }\end{array}$ & {$[46,69]$} \\
\hline Effects on sex behavior & Inhibits & Stimulates & {$[62]$} \\
\hline
\end{tabular}

a Abbreviations: Arc, arcuate nucleus; BW, body weight; Fl, food intake; GALP, Galanin-like peptide; GnRH, gonadotropin-releasing hormone; hDBB, horizontal limb of the diagonal band of Broca; i.c.v. intracerebroventricular; ME, median eminence; mPOA, medial preoptic area; PVN, paraventricular nucleus.

share partial sequence identity but differ in their distribution, pharmacology, specific G-protein-coupling and second messenger systems [21,25].

Until recently, galanin was the only known member of this unique family of neuropeptides. However, several reports of the interaction of unidentified molecules with galanin receptor subtypes, caused speculation about the existence of additional 'galanin-like peptides' [26]. In 1999, GALP, a galanin-like molecule was discovered by scientists in Japan [26].

\section{GALP and its binding to galanin receptors}

Ohtaki et al. discovered GALP while searching for unique molecules that bind and activate known galanin receptors. They named the new molecule GALP because of its shared partial sequence identity with galanin and its binding in vitro to two of the known galanin receptors [26]. Despite the partially shared sequence, GALP and galanin are encoded by different genes [27,28]. Fulllength GALP is cleaved from a larger precursor and comprises 60 amino acids. Residues 9-21 of GALP are identical to the biologically active $\mathrm{N}$-terminal portion (1-13) of galanin [29] (Figure 1). Unlike galanin, GALP has a non-amidated C-terminus. GALP binds in vitro to two subtypes of galanin receptor, GALR1 and GALR2 [25]. GALP binds to GALR1 with a lower affinity than galanin,

Galanin: ${ }^{1}$ GWTLNSAGYLLGP ${ }^{13}$ PHAVGNHRSFSDKNGLT

GALP: APAHRGRG ${ }^{9}$ GWTLNSAGYLLGP ${ }^{21}$ VLHLPQMGDADGKRETALEILDLWKAIDGLPYSHPPQPS

TRENDS in Endocrinology \& Metabolism

Figure 1. Amino acid sequences of galanin [16] and galanin-like peptide (GALP) [26]. Residues 1-13 of galanin and 9-21 of GALP (red) are identical. Residues 1-13 are thought to contain the biologically active portion of galanin. It remains to be determined whether this shared sequence is responsible for biological activity in GALP. but binds to GALR2 with a higher affinity than galanin [25]. The affinity of GALP for GALR3 is not known. It is plausible that one or more of these galanin receptors represent the endogenous physiological receptor for GALP; however, it is also conceivable that GALP has its own unique receptor(s).

Indirect evidence indicates that GALP is likely to have its own receptor. First, centrally administered galanin and GALP produce different patterns of Fos induction throughout the brain [30,31]. This observation indicates that galanin and GALP act through different targets and receptor-mediated processes in the brain to effect their biological actions. Second, centrally administered galanin and GALP produce widely disparate effects on several physiological systems, including differential effects on feeding, luteinizing hormone (LH) secretion and sexual behavior (Table 1), which indicates that these neuropeptides act through different receptors to produce their biological actions.

\section{Expression of GALP in the brain}

GALP is localized in the brain and its gene has been partially characterized in mice, rats, macaques and humans [32-36]. Cells in the Arc and median eminence of the rat, mouse and monkey express GALP mRNA [35,37]. In the Arc, GALP-containing neurons are distinct from other major populations of peptide-releasing cells and do not colocalize with NPY, galanin, somatostatin or GHRH $[25,33,34,38]$; however a few $(<10 \%)$ GALP neurons express $\alpha$-MSH [38]. The anatomical distribution of cells that contain GALP mRNA in the Arc in mice differs slightly from that in rats. In the mouse Arc, GALP cells are located more laterally and ventrally than in the rat. Careful, detailed studies of the distribution of GALP mRNA and GALP peptide are necessary to make definitive 
statements about their presence (or absence) in other regions of the nervous system.

\section{Expression of GALP in the posterior pituitary}

In the rat, GALP is expressed in the posterior pituitary (neurohypophysis) $[39,40]$. The discovery of GALP in the neurohypophysis and its apparent absence from the anterior pituitary is surprising because mRNAs that encode galanin, GALR1 and GALR2 are expressed in the anterior pituitary but not the neurohypophysis. In the latter, GALP is expressed in pituicytes. These are glial cells whose processes come in close contact with the nerve terminals of magnocellular neurons that project from the hypothalamic paraventricular and supraoptic nuclei. Expression of GALP mRNA in the rat neurohypophysis is induced dramatically following either salt-loading or water deprivation, which could indicate an important role for GALP in the regulation of vasopressin release and fluid balance [39]. Expression of GALP mRNA is also induced during lactation, which indicates that GALP regulates the secretion of oxytocin as well as vasopressin [28]. Notably, neither lactation nor salt-loading (or water deprivation) alters the expression of GALP mRNA in the Arc [28].

\section{Regulation of GALP mRNA in brain}

Metabolic hormones and fuels regulate the expression of GALP in the brain. Fasting reduces the expression of GALP mRNA in the Arc and leptin treatment during a fast can reverse this effect $[29,32,41]$. Leptin-deficient $o b / o b$ mice have profoundly reduced levels of GALP mRNA in the hypothalamus $[32,42]$, but treating these animals centrally (i.c.v) with leptin completely restores the expression of GALP mRNA to levels found in wild-type mice [29]. Rats and mice with dysfunctional leptin receptors ( $f a / f a$ and $d b / d b$, respectively) also have reduced expression of GALP mRNA [38]. Moreover, in both the rat and macaque, GALP-containing neurons express the leptin receptor $[33,35]$. These observations indicate that expression of GALP mRNA is regulated by direct actions of leptin on GALP-containing neurons in the brain.

Insulin also regulates the expression of GALP mRNA. Rats with streptozotocin-induced diabetes have greatly diminished expression of GALP mRNA in the Arc, which can be corrected with insulin treatment [43]. In addition, the administration of insulin directly into the brain during a fast stimulates the expression of GALP mRNA [43], which indicates that insulin also acts directly in the brain to induce the expression of GALP mRNA. Leptin and insulin share a common signaling pathway in the brain (phosphatidylinositol 3-kinase) [44,45], and it is conceivable that this is responsible for the common actions of leptin and insulin on the expression of GALP mRNA [43]. These studies demonstrate that metabolic hormones and metabolic fuels regulate GALP gene expression.

Thyroid hormones also influence the expression of GALP mRNA. Reduced circulating concentrations of thyroid hormones (caused by thyroidectomy) decrease hypothalamic levels of GALP mRNA, and replacement of thyroxine in thyroidectomized rats partially reverses this effect [28]. In addition, GALP delivered directly into the brain reduces the secretion of thyroid-stimulating hormone [46], again indicating that GALP plays a role in the neuroendocrine regulation of the hypothalamopituitary-thyroid axis. It is noteworthy that the expression of GALP is not influenced by circulating concentrations of glucocorticoids, sex steroids and growth hormone [28]; rather, its expression appears to be influenced predominantly by factors that reflect metabolic state.

\section{The effect of GALP on feeding, body weight and metabolism}

Centrally administered GALP has potent effects on feeding and body weight in rodents; however, the nature of these effects depends on the time-course and species. Within two hours of central administration to rats, GALP stimulates feeding in a manner similar to galanin [47]. This observation has been confirmed by several laboratories using GALP from different sources [48-50]. However, studies by Lawrence et al. [48] and Krasnow et al. [50] also document that GALP inhibits feeding and reduces body weight in rats $24 \mathrm{~h}$ after central injection. Together, these observations demonstrate that in the rat, centrally administered GALP exerts a biphasic effect on feeding, initially stimulating and later inhibiting this behavior. It has been argued that the biphasic effects of GALP might reflect the differential time-course of effects on the several receptor types that are activated by exogenously administered GALP [50]. For example, the initial stimulatory effect of GALP on feeding, which is reminiscent of that of galanin [51], might be attributable to the interaction of GALP with one or more galanin receptors, whereas the subsequent inhibition of feeding $24 \mathrm{~h}$ after injection of GALP reflects activity at its own, yet-to-be-identified receptor.

In mice, GALP elicits a dose-dependent suppression of feeding and body weight, both acutely (within $2 \mathrm{~h}$ ) and $24 \mathrm{~h}$ after a single central injection [50]. However, mice quickly become refractory to continued injections of GALP (twicedaily injections over four days), so that beyond the first $24 \mathrm{~h}$ period, food intake and body weight are not different between GALP- and vehicle-treated animals. Krasnow et al. [50] also demonstrated that the feeding response to central GALP treatment in mice is accompanied by significant changes in locomotor activity, which do not occur in the rat. Mice treated with nine injections of GALP over four days become quiet and unresponsive to stimulation immediately after each injection. However, they recover within a few hours and then seem to behave normally. This occurs with each subsequent injection, although the period of reduced locomotion that follows immediately after each injection appears to diminish after the ninth injection. By the fourth day of twice-daily injections of GALP, in the hours following the acute 'sedation'; GALP-treated mice become dramatically hyperactive relative to their vehicle-treated controls. This hyperactivity is reminiscent of the effect of amphetamines on motor function [52], and suggests activation of dopamine-containing pathways in the brain. It is also notable that GALP produces a conditioned taste aversion, which might also contribute to its inhibitory effect on feeding and body weight [50].

Administering GALP into the brain of $o b / o b$ mice for 14 days inhibits feeding and reduces body weight within 


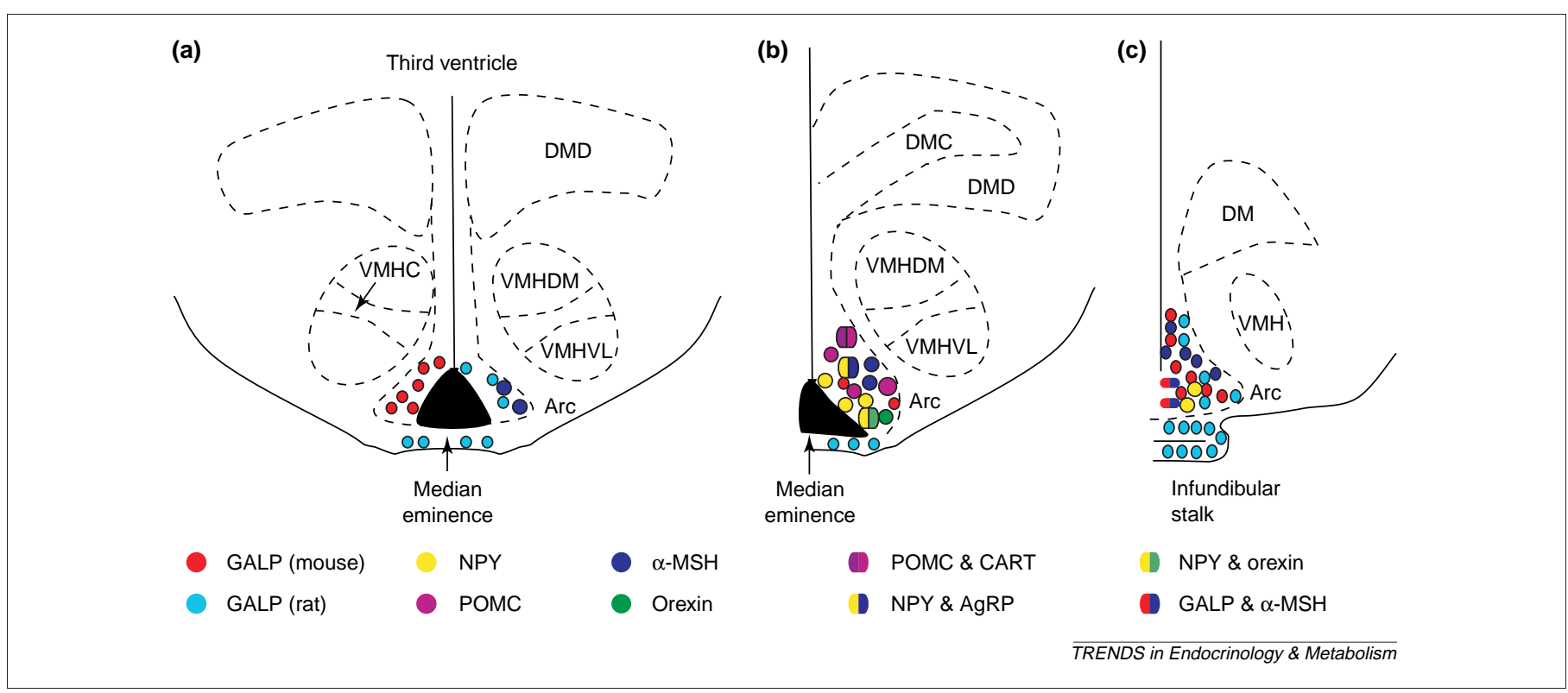

Figure 2. Localization of neuropeptides in the Arc. Each panel depicts a hypothalamic section (panel A is most rostral and panel $\mathrm{C}$ is most caudal). Colored dots demonstrate the approximate location of several neuropeptides. GALP is located in the median eminence and infundibular stalk of rats [33] but not mice [32]. GALP is located near several neuropeptides but is thought to colocalize only with $\alpha$-MSH [38]. GALP neurons do, however, express receptors for neuropeptides such as NPY [38] and orexin [63]. Several peptides colocalize, including CART and POMC, NPY and AgRP, and NPY and galanin (bicolored dots). Others are in close proximity to one another, such as POMC and NPY. [3-6]. Abbreviations: AgRP, agouti-related peptide; $\alpha-\mathrm{MSH}, \alpha$-melanocyte stimulating hormone; Arc, arcuate nucleus; CART, cocaine- and amphetamine-regulated transcript; DM, dorsomedial hypothalamus; DMC, dorsomedial hypothalamus (compact); DMD, dorsomedial hypothalamus (diffuse); GALP, galanin-like peptide; NPY, neuropeptide Y; POMC, proopiomelanocortin; VMH, ventromedial hypothalamus; VMHC, ventromedial hypothalamus (central); VMHDM, ventromedial hypothalamus (medial); VMHDM, ventromedial hypothalamus (dorsomedial); VMHVL, ventromedial hypothalamus (ventrolateral).

$24 \mathrm{~h}$ of the initial injection [53]. However, the feeding response to GALP does not adapt as quickly in $o b / o b$ as in wild-type mice. Leptin-deficient animals require considerably more time ( $\sim 10$ days) for feeding to be restored to the levels observed in animals that receive vehicle alone, but eventually they resume feeding to levels that are indistinguishable from that of controls. However, the body weight of $o b / o b$ mice does not fully recover during chronic treatment with GALP, and remains $\sim 12 \%$ lower than in vehicle-treated controls despite consumption of nearly identical amounts of food. This indicates that GALP has important effects on metabolism in addition to regulating of appetite and feeding.

GALP might also activate the sympathetic nervous system [53]. Chronic treatment of $o b / o b$ mice with GALP increases body temperature and stimulates downstream targets of sympathetic activation. Uncoupling protein 1 (UCP-1) acts in mitochondria to uncouple oxidative phosphorylation, so that fuel is oxidized to generate heat instead of ATP. Chronic treatment of $o b / o b$ mice with GALP increases the concentration of UCP-1 and its mRNA in brown adipose tissue, with an accompanying increase in multilocular brown adipocytes. The sustained reduction of body weight in animals receiving chronic GALP treatment is likely to be attributable to the effects of GALP on the sympathetic nervous system [53].

\section{GALP and neuroendocrine regulation of the reproductive axis}

Reproduction is gated by physiological factors associated with nutrition, energy reserves and metabolic rate; however, the cellular and molecular mechanisms that link metabolism and reproduction are not fully understood.
The activity of GnRH-containing neurons is influenced by metabolic hormones, including leptin and insulin [54-59]. Centrally administered GALP stimulates LH secretion through a GnRH-dependent mechanism in the rat [46] and monkey [60]. GALP-containing fibers are found in close apposition to a subset of $\mathrm{GnRH}$ neurons in the medial preoptic area (mPOA) and the bed nucleus of the stria terminalis (BST) [33,61]. Moreover, centrally administered GALP induces Fos expression in a subset of GnRH neurons [61]. Likewise, in the mouse, centrally administered GALP stimulates LH and testosterone secretion, demonstrating a similar effect of GALP on the neuroendocrine reproductive axis [50]. Other recent studies demonstrate that leptin stimulates the release of GALP and $\mathrm{GnRH}$ from hypothalamic explants in vitro, and that GALP antiserum blocks the stimulatory effects of leptin on GnRH secretion [46], thus, corroborating earlier suggestions that GALP plays an important role in mediating the effects of leptin on the neuroendocrine reproductive axis. The effects of GALP on GnRH secretion in vitro are attenuated only partially by a potent galanin receptor antagonist, galantide [46], which bolsters the suggestion that GALP has its own unique receptor. GALP might also play a role in sexual behavior because centrally administered GALP increases mounting, intromissions and ejaculatory function in male rats [62]. Taken together, these observations demonstrate that GALP exerts a direct and powerful activational effect on the reproductive system.

Hypothalamic circuitry linked to GALP-positive neurons The afferent and efferent connections of GALP-positive neurons are yet to be fully elucidated. Immunocytochemistry reveals that GALP-positive neurons in the Arc project 


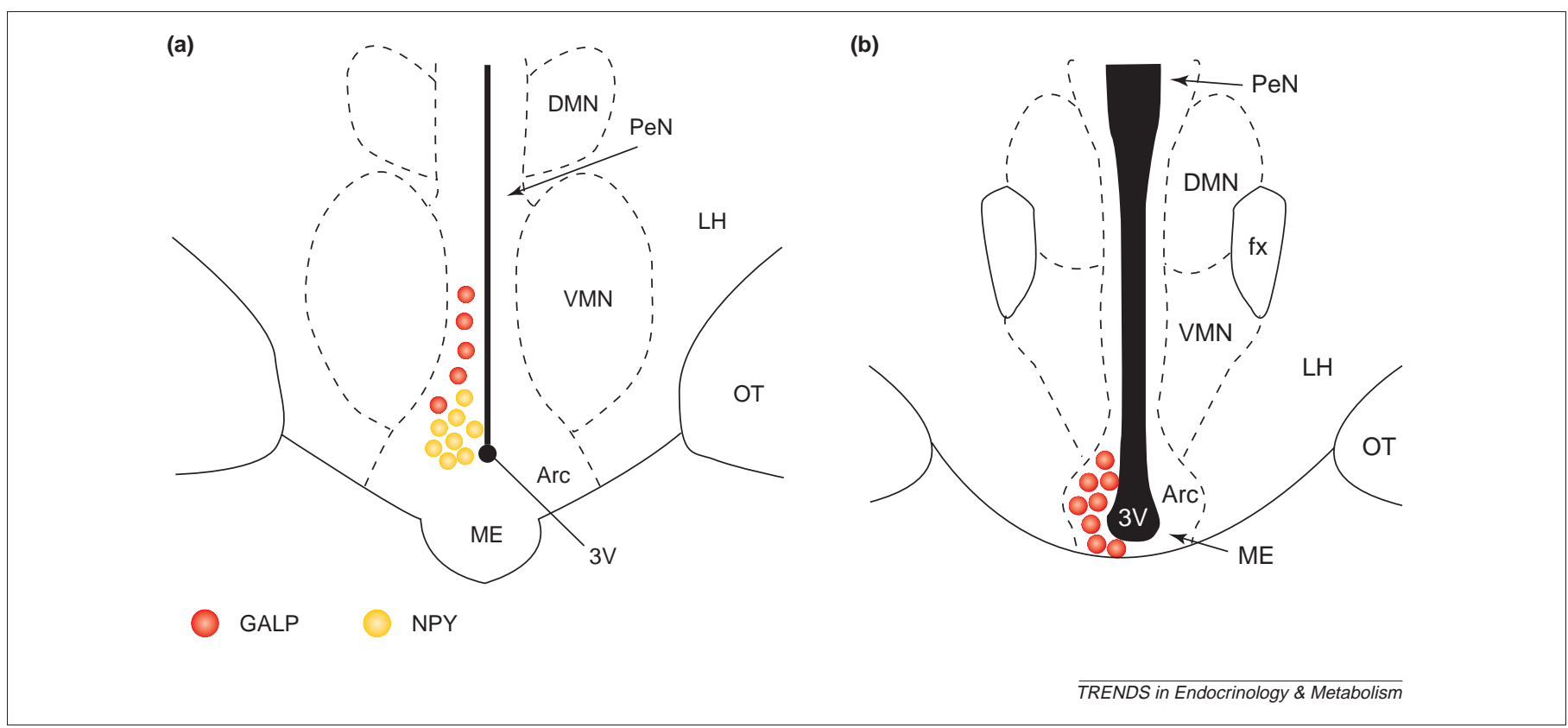

Figure 3. Localization of GALP and NPY in the macaque. Panels depict rostral (a) and caudal (b) hypothalamic sections to demonstrate the approximate location of GALP (red circles) and NPY (yellow circles). Although they localize in close proximity to each other, they represent separate and distinct cell groups in the Arc: GALP-positive neurons are localized more dorsal-medially, whereas NPY-positive neurons are localized more ventral-medially. The number of NPY-positive neurons reduces with caudal progression through the Arc. GALP-positive neurons do express NPY receptors [60]. Abbreviations: 3V, third ventricle, Arc, arcuate nucleus; DMN, dorsomedial nucleus; fx, fornix; GALP, galanin-like peptide; LH, lateral hypothalamus; ME, median eminence; NPY, neuropeptide Y; OT, optic tract; PeN, periventricular nucleus; VMN, ventromedial nucleus; $\mathrm{VMH}$, ventromedial hypothalamus.

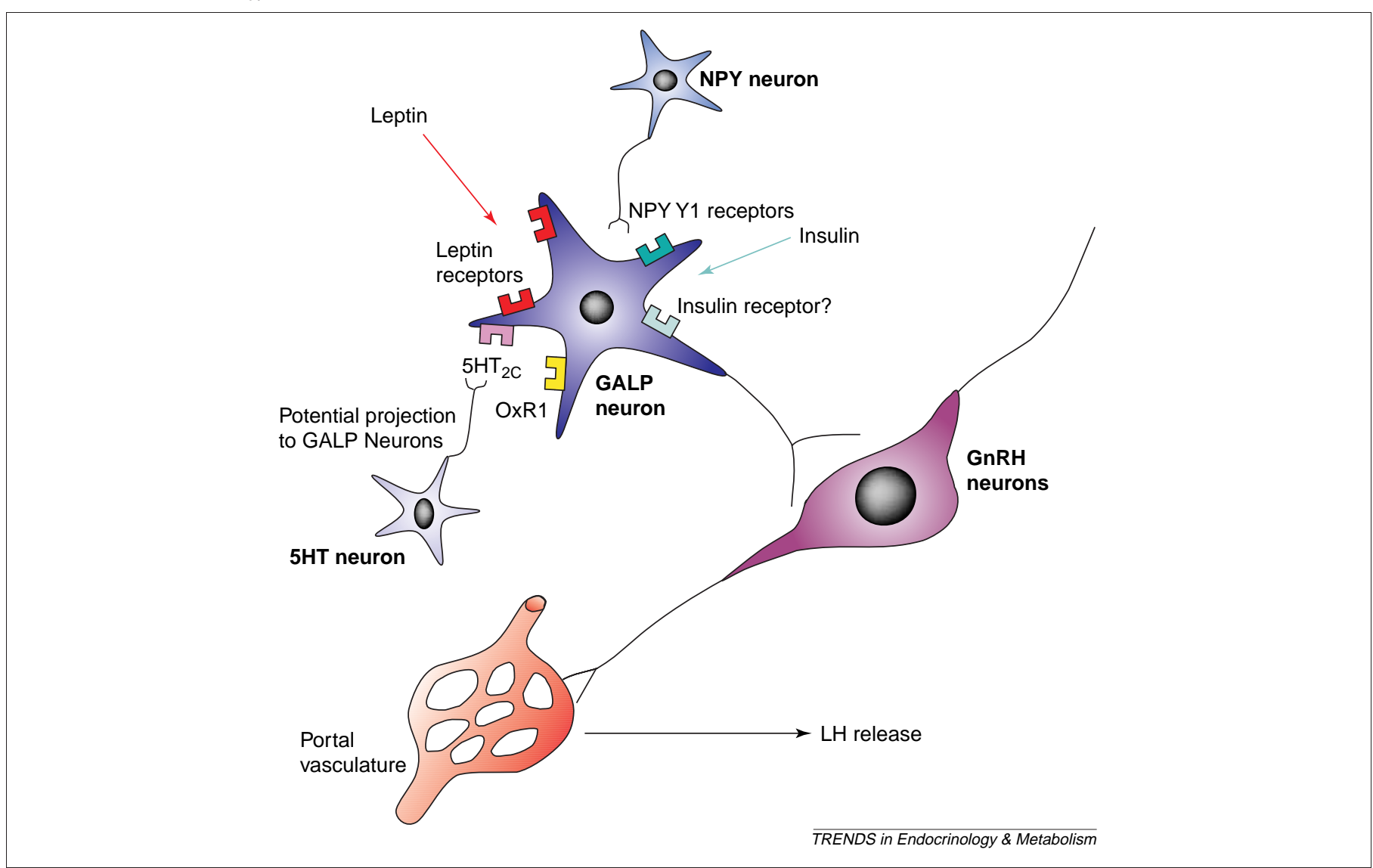

Figure 4. Proposed interactions between galanin-like peptide (GALP)-positive neurons and other neuroendocrine mediators. The GALP-positive neuron in this figure expresses receptors for leptin [29], neuropeptide Y (NPY Y1) [38], 5-hydroxytryptamine (5- $\mathrm{HT}_{2 \mathrm{C}}$ ) [M. Cunningham, PhD Thesis, University of Washington, 2003] and orexin (OxR1) [63]. The majority (>85\%) of GALP-positive neurons express leptin receptors [25], fewer express receptors for NPY, orexin and 5-HT. Although insulin also alters expression of the gene that encodes GALP [43], no insulin receptors have been identified on GALP-positive neurons. Leptin is shown with a red arrow because most GALPpositve neurons express leptin receptors and it is likely to have a large influence on the activity of GALP-positive neurons. Projections from GALP-positive neurons to neurons that contain gonadotropin-releasing hormone $(\mathrm{GnRH})[46,61]$ stimulate the release of $\mathrm{GnRH}$ into the portal vasculature, which, in turn, stimulates the release of luteinizing hormone (LH) from the pituitary. As a result of the neuronal contacts between GALP and other factors, it is likely that GALP is a link in the integration of energy balance and reproductive function. 
to several areas of the basal forebrain, including the PVN, lateral septal nucleus, BST and mPOA [33]. Following the central administration of GALP, Fos activation has been described in the horizontal limb of the diagonal band of Broca, caudal preoptic area, Arc and median eminence [30,31]. These regions could be direct targets of GALP projections; however, it is also conceivable that they reflect second-order neurons in the downstream signaling pathway of GALP. The phenotypic identity of neurons that are targets for GALP are yet to be elucidated.

Afferent inputs to GALP-positive neurons are only partially known. In the monkey, it appears that many ( $>40 \%)$ GALP neurons express the NPY Y1 receptor [60] and some $(\sim 25 \%)$ GALP-positive neurons express the 5-hydroxytryptamine 5- $\mathrm{HT}_{2 \mathrm{C}}$ receptor [60]. Fibers from orexin-positive neurons appear to be in close apposition to GALP cell bodies in the Arc, and a few $(<15 \%)$ GALPpositive neurons appear to express the orexin type 1 receptor [63]. These observations indicate that GALPpositive neurons receive input from a variety of neurotransmitter systems in the brain (Figure 2 and Figure 3), notably those that are implicated in the neuroendocrine regulation of metabolism and reproduction [25].

\section{GALP is a molecular link between metabolism and reproduction}

GALP-positive neurons are attractive candidates for mediating the effects of metabolism on the neuroendocrine reproductive axis. First, these cells are direct targets for regulation by metabolic hormones (leptin, insulin and thyroid hormone), whose signaling is essential to support normal reproductive function [55,56,64-68]. Second, GALP-positive neurons, whose cell bodies reside in the Arc, send projections that terminate in the immediate vicinity of GnRH-positive neurons in the mPOA. Finally, GALP itself can stimulate GnRH secretion and sexual behavior. Thus, metabolically sensitive, GALP-containing neurons could be a conduit that relays important information about the status of fuel reserves to GnRHpositive neurons and thereby governs the activity of the reproductive axis as a function of metabolic state (Figure 4).

\section{Acknowledgements}

We thank Stephanie M. Krasnow, Gregory S. Fraley, Matthew J. Cunningham and Simina M. Popa for their technical and critical expertise. This work was supported by grants from the National Science Foundation (IBN-0110686), US Public Health Service NIH (R01-HD-27142 and RO1-DK-08), Specialized Cooperative Centers Program for Reproductive Research (U54-HD-12629) and National Research Service Award T32-GM-07270 from the National Institute of General Medicine and Science.

\section{References}

1 Sawchenko, P.E. (1998) Toward a new neurobiology of energy balance, appetite, and obesity: the anatomists weigh in. J. Comp. Neurol. 402, $435-441$

2 Porte, D., Jr., et al. (2002) Leptin and insulin action in the central nervous system. Nutr Rev. 60, S20-29; discussion S68-84, 85-27.

3 Williams, G. et al. (2001) The hypothalamus and the control of energy homeostasis: different circuits, different purposes. Physiol. Behav. 74, 683-701

4 Cone, R.D. et al. (2001) The arcuate nucleus as a conduit for diverse signals relevant to energy homeostasis. Int. J. Obes. Relat. Metab. Disord. 25 (Suppl. 5), S63-S67
5 McMinn, J.E. et al. (2000) Neuroendocrine mechanisms regulating food intake and body weight. Obes. Rev. 1, 37-46

6 Druce, M. et al. (2003) Central regulators of food intake. Curr. Opin. Clin. Nutr. Metab. Care 6, 361-367

7 Elmquist, J.K. (2001) Hypothalamic pathways underlying the endocrine, autonomic, and behavioral effects of leptin. Int. J. Obes. Relat. Metab. Disord. 25 (Suppl. 5), S78-S82

8 Kalra, S.P. et al. (1998) Neuroendocrine interactions between galanin, opioids, and neuropeptide $\mathrm{Y}$ in the control of reproduction and appetite. Ann. N. Y. Acad. Sci. 863, 236-240

9 Reiter, E.O. (1987) Neuroendocrine control processes. Pubertal onset and progression. J. Adolesc. Health Care 8, 479-491

10 Durando, P. et al. (1989) Acute administration of alpha-melanotropin exerts a stimulatory control on puberty. Acta Endocrinol. (Copenh.) $120,661-666$

11 Conover, C.D. et al. (1993) Beta-endorphin regulation of luteinizing hormone-releasing hormone release at the median eminence in ewes: immunocytochemical and physiological evidence. Neuroendocrinology 57, 1182-1195

12 Sahu, A. et al. (1994) Hypothalamic neuropeptide-Y gene expression increases before the onset of the ovarian steroid-induced luteinizing hormone surge. Endocrinology 134, 1018-1022

13 Kandeel, F.R.et al. (1997) The interaction between beta-endorphin and gonadal steroids in regulation of luteinizing hormone (LH) secretion and sex steroid regulation of $\mathrm{LH}$ and proopiomelanocortin peptide secretion by individual pituitary cells. Endocrinology 138, 649-656

14 Tatemoto, K. et al. (1983) Galanin - a novel biologically active peptide from porcine intestine. FEBS Lett. 164, 124-128

15 Vrontakis, M.E. (2002) Galanin: a biologically active peptide. Curr. Drug Target CNS Neurol. Disord. 1, 531-541

16 Bedecs, K. et al. (1995) Galanin-10 years with a neuroendocrine peptide. Int. J. Biochem. Cell Biol. 27, 337-349

17 Finn, P.D. et al. (2000) Galanin's functional significance in the regulation of the neuroendocrine reproductive axis of the monkey. Neuroendocrinology 71, 16-26

18 Niimi, M. et al. (1990) Immunohistochemical identification of galanin and growth hormone-releasing factor-containing neurons projecting to the median eminence of the rat. Neuroendocrinology 51, 572-575

19 Landry, M. et al. (2003) Differential routing of coexisting neuropeptides in vasopressin neurons. Eur. J. Neurosci. 17, 579-589

20 Ohhashi, T. et al. (1985) Galanin potentiates electrical stimulation and exogenous norepinephrine-induced contractions in the rat vas deferens. Regul. Pept. 12, 163-171

21 Branchek, T.A. et al. (2000) Galanin receptor subtypes. Trends Pharmacol. Sci. 21, 109-117

22 Crawley, J.N. et al. (2002) Galanin overexpressing transgenic mice. Neuropeptides $36,145-156$

23 Kalra, S.P. et al. (1996) Nutritional infertility: the role of the interconnected hypothalamic neuropeptide Y-galanin-opioid network. Front. Neuroendocrinol. 17, 371-401

24 Cheung, C.C. (1996) Galanin an unassuming neuropeptide moves to center stage in reproduction. Trends Endocrinol. Metab. 7, 301-306

25 Gundlach, A.L. (2002) Galanin/GALP and galanin receptors: role in central control of feeding, body weight/obesity and reproduction? Eur. J. Pharmacol. 440, 255-268

26 Ohtaki, T. et al. (1999) Isolation and cDNA cloning of a novel galaninlike peptide (GALP) from porcine hypothalamus. J. Biol. Chem. 274, 37041-37045

27 Evans, H. et al. (1993) Genomic organization and localization of the gene encoding human preprogalanin. Genomics 18, 473-477

28 Cunningham, M.J.et al. (2004) Regulation of galanin-like peptide gene expression by pituitary hormones and their downstream targets. J. Neuroendocrinol. 16, 10-18

29 Jureus, A. et al. (2000) Galanin-like peptide (GALP) is a target for regulation by leptin in the hypothalamus of the rat. Endocrinology 141, 2703-2706

30 Fraley, G.S. et al. (2003) Differential patterns of Fos induction in the hypothalamus of the rat following central injections of galanin-like peptide and galanin. Endocrinology 144, 1143-1146

31 Lawrence, C.B. et al. (2003) Intracerebroventricular galanin-like peptide induces different brain activation compared with galanin. Endocrinology 144, 3977-3984

32 Jureus, A. et al. (2001) Distribution and regulation of galanin-like 
peptide (GALP) in the hypothalamus of the mouse. Endocrinology 142 , $5140-5144$

33 Takatsu, Y. et al. (2001) Distribution of galanin-like peptide in the rat brain. Endocrinology 142, 1626-1634

34 Larm, J.A. et al. (2000) Galanin-like peptide (GALP) mRNA expression is restricted to arcuate nucleus of hypothalamus in adult male rat brain. Neuroendocrinology $72,67-71$

35 Cunningham, M.J. et al. (2002) Cloning and distribution of galaninlike peptide mRNA in the hypothalamus and pituitary of the macaque. Endocrinology 143, 755-763

36 Berger, A. et al. (2003) Galanin and galanin receptors in human gliomas. Acta Neuropathol. (Berl.) 105, 555-560

37 Kerr, N.C. et al. (2000) Galanin-like peptide (GALP) is expressed in rat hypothalamus and pituitary, but not in DRG. Neuroreport 11, 3909-3913

38 Takenoya, F. et al. (2002) Galanin-like peptide is co-localized with alpha-melanocyte stimulating hormone but not with neuropeptide $Y$ in the rat brain. Neurosci. Lett. 331, 119-122

39 Fujiwara, K. et al. (2002) Immunocytochemical localization of a galanin-like peptide (GALP) in pituicytes of the rat posterior pituitary gland. Neurosci. Lett. 317, 65-68

40 Shen, J. et al. (2001) Galanin-like peptide mRNA in neural lobe of rat pituitary. Increased expression after osmotic stimulation suggests a role for galanin-like peptide in neuron-glial interactions and/or neurosecretion. Neuroendocrinology 73, 2-11

41 Cunningham, M.J. et al. (2002) Galanin-like peptide (GALP) mRNA is reduced by fasting in the arcuate nucleus of the macaque. 84th Annual Meeting of the Endocrine Society

42 Kumano, S. et al. (2003) Changes in hypothalamic expression levels of galanin-like peptide in rat and mouse models support that it is a leptintarget peptide. Endocrinology 144, 2634-2643

43 Fraley, G.S. et al. (2004) The effects of diabetes and insulin on the expression of galanin-like peptide (GALP) in the hypothalamus of the rat. Diabetes 53, 1237-1242

44 Niswender, K.D. et al. (2001) Intracellular signalling. Key enzyme in leptin-induced anorexia. Nature 413, 794-795

45 Niswender, K.D. et al. (2003) Insulin activation of phosphatidylinositol 3-kinase in the hypothalamic arcuate nucleus: a key mediator of insulin-induced anorexia. Diabetes 52, 227-231

46 Seth, A. et al. (2004) Galanin-like peptide stimulates the release of gonadotropin-releasing hormone in vitro and may mediate the effects of leptin on the hypothalamo-pituitary-gonadal axis. Endocrinology $145,743-750$

47 Matsumoto, Y. et al. (2002) Galanin-like peptide stimulates food intake in the rat. Neurosci. Lett. 322, 67-69

48 Lawrence, C.B. et al. (2002) Centrally administered galanin-like peptide modifies food intake in the rat: a comparison with galanin. J. Neuroendocrinol. $14,853-860$

49 Seth, A. et al. (2003) Effects of galanin-like peptide on food intake and the hypothalamo-pituitary-thyroid axis. Neuroendocrinology 77 , $125-131$

50 Krasnow, S.M. et al. (2003) A role for galanin-like peptide in the integration of feeding, body weight regulation, and reproduction in the mouse. Endocrinology 144, 813-822

51 Schick, R.R. et al. (1993) Effect of galanin on food intake in rats: involvement of lateral and ventromedial hypothalamic sites. Am. J. Physiol. 264, R355-R361

52 Compan, V. et al. (2003) Enkephalin contributes to the locomotor stimulating effects of 3,4-methylenedioxy-N-methylamphetamine. Eur. J. Neurosci. 18, 383-390

53 Hansen, K.R. et al. (2003) Activation of the sympathetic nervous system by galanin-like peptide-a possible link between leptin and metabolism. Endocrinology 144, 4709-4717

54 Chehab, F.F. (2000) Leptin as a regulator of adipose mass and reproduction. Trends Pharmacol. Sci. 21, 309-314

55 Barash, I.A. et al. (1996) Leptin is a metabolic signal to the reproductive system. Endocrinology 137, 3144-3147

56 Smith, G.D. et al. (2002) Leptin regulation of reproductive function and fertility. Theriogenology $57,73-86$

57 Foster, D.L. et al. (1999) Physiological perspectives on leptin as a regulator of reproduction: role in timing puberty. Biol. Reprod. 60, $205-215$

58 Nagatani, S. et al. (1998) Evidence for GnRH regulation by leptin leptin administration prevents reduced pulsatile LH secretion during fasting. Neuroendocrinology 67, 370-376

59 Sullivan, S.D. et al. (2003) Metabolic regulation of fertility through presynaptic and postsynaptic signaling to gonadotropin-releasing hormone neurons. J. Neurosci. 23, 8578-8585

60 Cunningham, M.J. et al. (2004) Galanin-like peptide as a possible link between metabolism and reproduction in the macaque. $J$ of Clin Endocrinol Metabol. 89, 1760-1766

61 Matsumoto, H. et al. (2001) Stimulation effect of galanin-like peptide (GALP) on luteinizing hormone-releasing hormone-mediated luteinizing hormone (LH) secretion in male rats. Endocrinology 142, $3693-3696$

62 Fraley, G.S. et al. (2003) Galanin-like peptide as a central mediator of metabolism and reproductive behavior. Society for Neuroscience, $33^{\text {rd }}$ Annual Meeting, Abstract 77

63 Takenoya, F. et al. (2003) Galanin-like peptide is target for regulation by orexin in the rat hypothalamus. Neurosci. Lett. 340, $209-212$

64 Friedman, J.M. (2002) The function of leptin in nutrition, weight, and physiology. Nutr. Rev. 60, S1-14; discussion S68-84, 85-17

65 Burks, D.J. et al. (2000) IRS-2 pathways integrate female reproduction and energy homeostasis. Nature 407, 377-382

66 Bruning, J.C. et al. (2000) Role of brain insulin receptor in control of body weight and reproduction. Science $289,2122-2125$

67 Krassas, G.E. et al. (2003) Thyroid disease and male reproductive function. J. Endocrinol. Invest. 26, 372-380

68 Weber, G. et al. (2003) Thyroid function and puberty. J. Pediatr. Endocrinol. Metab. 16 (Suppl. 2), 253-257

69 Rajendren, G. and Gibson, M.J. (1999) Expression of galanin immunoreactivity in gonadotropin releasing hormone neurons in mice: a confocal microscopic study. Brain Res. $821,270-276$ 